\title{
A CONVERGÊNCIA CUIDADO-EDUCAÇÃO-POLITICIDADE: UM DESAFIO A SER ENFRENTADO PELOS PROFISSIONAIS NA GARANTIA AOS DIREITOS À SAÚDE DAS PESSOAS PORTADORAS DE ESTOMIAS \\ THE HEALTH CARE-EDUCATION-POLITICS CONVERGENCE: A CHALLENGE TO BE FACED BY PROFESSIONALS WHEN ASSURING THE HEALTH RIGHTS OF OSTOMIZED PEOPLE \\ LA CONVERGENCIA CUIDADO-EDUCACIÓN-POLITICIDAD: UN RETO A SER ENFRENTADO POR LOS PROFESIONALES EN LA GARANTÍA A LOS DERECHOS DE LA SALUD DE LAS PERSONAS PORTADORAS DE OSTOMÍAS
}

\author{
Roseney Bellato', Wilz̧a Rocha Pereira², Sônia Ayako Tao Maruyama³, Phaedra Castro de Oliveira ${ }^{4}$
}

\footnotetext{
1 Doutora em Enfermagem. Docente da Faculdade de Enfermagem (FAEN) e do Programa de Pós-Graduação em Enfermagem, Nível Mestrado, da Universidade Federal de Mato Grosso (UFMT). Coordenadora do Grupo de Pesquisa "Enfermagem, Saúde e Cidadania" (GPESC), cadastrado na Plataforma Lattes/CNPq.

2 Doutora em Enfermagem. Docente FAEN e do Programa de Pós-Graduação em Enfermagem, Nível Mestrado, da UFMT.Vicecoordenadora do GPESC.

3 Doutora em Enfermagem. Docente FAEN e do Programa de Pós-Graduação em Enfermagem, Nível Mestrado, da UFMT.Membro do GPESC

4 Acadêmica do $8^{\circ}$ semestre do Curso de Graduação em Enfermagem da FAEN. Bolsista do Programa Institucional de Bolsas de Iniciação Científica do Conselho Nacional de Pesquisa.
}

PALAVRAS-CHAVE: Enfermagem. Ostomia. Educação em saúde. Cuidados de enfermagem.

KEYWORDS: Nursing. Ostomy. Health education. Nursing care.

PALABRAS CLAVE: Enfermería. Ostomía. Educación en salud. Atención de enfermería.

Endereço: Roseney Bellato Av. Anita Garibaldi, R. B, 85 78.075-190 - Jardim Universitário, Cuiabá, MT.

E-mail: roseney@terra.com.br
RESUMO: Partimos do pressuposto de que há uma estreita convergência entre educação-cuidadopoliticidade quando se deseja a garantia aos direitos das pessoas em situações crônicas de saúde. Assim, foi objetivo desta reflexão evidenciar a imbricação que há entre o cuidado em saúde e em enfermagem, a educação para a saúde e a politicidade que os permeia. Partindo da apresentação parcial dos dados de uma pesquisa exploratória realizada junto à pessoas portadoras de estomia em um hospital público do Estado de Mato Grosso pudemos discutir a estreita relação que há entre a educação, o cuidado e a formação do sujeito político, seja ele aluno, profissional ou usuário de serviço de saúde.

ABSTRACT: We began with the presupposition that there is a very close convergence between education-care-politicity when assuring the rights of people with chronic health conditions. So, the aim of this study was to reflect on the imbrication between health and nursing care, health education and their politicity. Beginning with the partial presentation of data from exploratory research on ostomized people in a public hospital in the state of Mato Grosso, we could discuss about this narrow relation between the education, the care and the formation of political individuals, regardless of being a graduate, a professional or an user of health services.

RESUMEN: Empezamos a partir del presupuesto de que existe una estrecha convergencia entre la educación-cuidado-politicidad cuando se desea la garantía a los derechos de las personas en situaciones crónicas de salud. El objetivo de esta reflexión fue evidenciar la imbricación que existe entre el cuidado en la salud y en la enfermería, la educación para la salud y la politicidad que los orienta. Partiendo de la presentación parcial de los datos de una investigación exploratoria junto a personas portadoras de ostomías en un hospital publico del Estado de Mato Grosso, empezamos la discusión acerca de la relación que existe entre la educación, el cuidado y la formación de sujeto político, sea el alumno, el profesional o el usuario de los servicios de la salud. 


\section{CONSIDERAÇÕES INICIAIS}

Muito se tem tratado na saúde, e particularmente na Enfermagem, sobre a estreita relação existente entre cuidado e educação. Além da complexidade que ambos os conceitos comportam, quando vistos sob a ótica da enfermagem entendemos que a educação ainda precisa ser compreendida no seu desdobramento próprio: o primeiro voltado para a formação dos profissionais da área, de cunho mais acadêmico-científico e o segundo focalizado na educação para a saúde, voltada para o autocuidado, logo, um componente que auxilia a construir a autonomia das pessoas no cuidado à sua saúde.

Ao longo de nossa atuação profissional temos constatado que as dimensões que ligam cuidado e educação são inseparáveis, pois a formação profissional da enfermagem está focalizada no cuidado do outro, assim, apreende-se em um movimento dinâmico e dialógico, tanto a tecnologia do cuidar, como a ética humanística necessária a um cuidado que se quer emancipador e solidário. Esta última dimensão nos aponta ainda para a politicidade que o cuidado em saúde implica, exigindo um deslocamento no sentido de construir uma outra racionalidade, mais focalizada na mutualidade, na solidariedade e simetria entre sujeitos semelhantes, mas com necessidades e limitações diferentes. Politicidade é por nós entendida como a habilidade humana de saber pensar e intervir, no sentido de atingir níveis crescentes de autonomia individual e coletiva, que permitem conduzir história própria [...] mas vale lembrar que a autonomia não é situação dada e muito menos completa, mas processo interminável [...]. ${ }^{1}$

O portador de um problema crônico de saúde, como é o caso do portador de estomias, se vê limitado no exercício da sua autonomia nos modos de levar a vida cotidiana pela oferta inconstante dos dispositivos de estomias pelo sistema de saúde, o que o leva a pressionar constantemente o serviço e os profissionais envolvidos no seu cuidado para resolver suas necessidades. Os profissionais, por sua vez, se vêem limitados por não conseguirem atuar utilizando plenamente seus conhecimentos e habilidades, assim se configurando uma situação de constrangimento para ambos que, se adequadamente trabalhada, pode aproximar usuários e trabalhadores.
Um exemplo desse trabalho foi a agregação política entre usuários e trabalhadores que resultou na criação da Associação Matogrossense de Ostomizados (AMO), uma iniciativa dos trabalhadores que incentivaram e apoiaram, política e tecnicamente, o processo de constituição dessa Associação, que atualmente funciona de forma autônoma e independente dos profissionais de saúde. Nessa iniciativa específica evidenciamos que o processo de cuidado-educação, no seu sentido amplo, foi e continua sendo essencialmente político, visto que representa a formação de sujeitos capazes de fazer história própria individual e coletivamente. ${ }^{2}$

Para tanto, o processo de cuidar implica estar em relação solidária com aquele que é cuidado, importar-se com ele, compreendê-lo em suas necessidades próprias, respeitar suas limitações e estimular suas potencialidades. ${ }^{3} \mathrm{Na}$ vigência de uma situação de doença crônica essas dimensões se tornam ainda mais prementes, visto que o cuidado a ser oferecido deverá abranger particularmente o aprendizado para o cuidar-se com segurança e de maneira contínua. Esse aprendizado deve se dar de maneira paulatina e cuidadosa, calcado no estímulo à autonomia da pessoa portadora de um problema crônico de saúde, ou seja, o profissional deve co-responsabilizar-se para que essa pessoa saiba, progressivamente, desempenhar o autocuidado adequado e seguro para si mesma nos aspectos em que seja ou que venha a ser capaz com o apoio profissional.

No contexto da pesquisa maior que estamos realizando ${ }^{*}$ a ser descrita de forma preliminar na presente reflexão, o cuidar está estreitamente relacionado em educar o sujeito para emancipar-se, possibilitando a sua inserção em novas redes sociais, uma vez que partimos do pressuposto que esses são sujeitos capazes de decisão, diálogo e ação. ${ }^{3}$ Assim, ao estimular o exercício efetivo da cidadania desses sujeitos, através do estímulo e apoio à criação da $\mathrm{AMO}$, desenvolveu-se uma ação para além do cuidado voltado ao problema do usuário do serviço ambulatorial e que aponta para a convergência cuidado-educação-politicidade.

Percebemos que neste contexto o cuidado implica em educar o sujeito para emancipar-se, deixando este de ser tutelado e dependente do profissional, pois desenvolveu sua auto-estima de modo a exercer o con-

\footnotetext{
* Maruyama SAT, Bellato R, Pereira WR, Oliveira, PC. Proposta metodológica de capacitação dos portadores de ostomias na atenção aos seus direitos como usuários de serviços públicos de saúde [relatório parcial de pesquisa]. Cuiabá: Pró-Reitoria de Pesquisa UFMT. Pesquisa financiada pela Fundação de Apoio à Pesquisa do Estado de Mato Grosso (FAPEMAT); 2005.
}

Texto Contexto Enferm, Florianópolis, 2006 Abr-Jun; 15(2):334-42. 
trole de sua própria vida, e, portanto, o auto-cuidado, ainda que com as limitações impostas pela doença. No que se refere aos profissionais de saúde pudemos perceber que estes vêm trabalhando de forma criativa as diversas carências que encontram no exercício do seu trabalho cotidiano interagindo diretamente com as pessoas portadores de estomias, inclusive na confecção de dispositivos que são onerosos e nem sempre disponíveis na quantidade necessária aos mesmos. Essas redes de ação, cuidado e socialização aproximam usuários, acadêmicos docentes e trabalhadores e contribuem sobremaneira para uma interação mais cidadã entre todos.

\section{METODOLOGIA}

Apoiando-nos na nossa atuação como enfermeiras, docentes e pesquisadoras junto a um Ambulatório de Estomias de um hospital público do Estado de Mato Grosso, recorremos aos resultados obtidos a partir de uma das pesquisas subsidiárias ao projeto maior que estamos efetivando junto aos usuários desse ambulatório para desenvolvermos a presente reflexão teórica, que evidencia a estreita relação que pode haver entre o cuidado em saúde e em enfermagem, a educação para a saúde e a politicidade que pode, se adequadamente trabalhada, permear esses processos.

Os dados inicialmente obtidos foram organizados em três categorias: realização da estomia; cuidados e orientações; direitos dos estomizados. No entanto, para a finalidade desta reflexão teórica recorremos apenas aos dados referentes ao perfil das pessoas portadoras de estomias e aqueles referentes à realização da estomia e aos cuidados e orientações oferecidos pelos profissionais de saúde a essas pessoas.

Entendemos que esse recorte foi importante para podermos dar o necessário destaque as dimensões que se tornam nosso foco de interesse, quais sejam, o cuidado em saúde e em enfermagem, a educação para a saúde e a politicidade que os permeia com vistas à efetivação e ampliação da cidadania das pessoas portadoras de estomia e o importante papel que os profissionais de saúde desempenham nesse processo.

A pesquisa nos aponta para uma "fotografia" de uma situação particular da assistência à saúde prestada pelos profissionais no Ambulatório de Estomia da instituição. Com ela estamos reiterando o compromisso do Grupo de Pesquisa Enfermagem, Saúde e Cidadania (GPESC), ao qual pertencemos, de operar mudanças nessa realidade tanto no que se refere aos cuidados de enfermagem prestado às pessoas portadoras de estomia, como também na efetivação e ampliação dos seus direitos. Outro elemento importante é que estamos aprofundando nossos referenciais teóricos e metodológicos acerca deste complexo processo também junto aos alunos e trabalhadores, de maneira que possam fazer-se cidadão e exercer a cidadania própria assim como, ao mesmo tempo, contribuir para a cidadania do próximo, o usuário dos serviços onde atuamos.

No estudo originário desta reflexão todos os preceitos éticos da Resolução 196/96 do Conselho Nacional de Saúde que trata da pesquisa com seres humanos foram respeitados integralmente, havendo a assinatura do Termo de Consentimento Livre e Esclarecido tanto pelas pesquisadoras quanto pelos entrevistados, bem como aprovação do Projeto de Pesquisa por um Comitê de Ética em Pesquisa. ${ }^{4}$

\section{UM PONTO DE PARTIDA: O PERFIL DOS USUÁRIOS COMO A "FOTOGRAFIA" DE UMA SITUAÇÃO EM MUDANÇA}

O termo estomia é de origem grega e significa abertura artificial de um órgão interno na superfície do corpo, criada cirurgicamente e sua denominação depende do órgão que seja exteriorizado. As razões que levam a necessidade de confecção de uma estomia são variadas, mas predominam as neoplasias e os ferimentos por arma de fogo ou branca, podendo a mesma ser temporária, cujo fechamento se dará em um tempo variável de acordo com as condições relacionadas ao portador, ou definitiva, sendo que ela permanecerá durante toda a vida da pessoa.

Independentemente de suas características a realização da estomia é sempre um acontecimento traumático, pois ela acarreta mudanças que repercutirão em todos os níveis da vida da pessoa tais como: necessidade de realização do autocuidado com a estomia, aquisição de material apropriado para a contenção das fezes ou urina, adequação alimentar, convivência com a perda do controle da continência intestinal ou vesical, eliminação de odores, alteração da imagem corporal, bem como alteração das atividades sociais, sexuais e cotidianas. $^{5}$

Nesta reflexão recorremos aos dados do perfil dos sujeitos entrevistados no que se refere à idade, sexo, grau de escolaridade e renda familiar, problematizando-os a partir da convergência cuidadoeducação-politicidade. Também alguns dados relativos a estomia favorecem a compreensão desse perfil, tais 
como, tipo da estomia, motivo e tempo de sua realização e se é temporária ou definitiva, bem como as orientações oferecidas às pessoas portadoras de estomia pelos profissionais de saúde.

Essa problematização nos auxiliou a refletir sobre a importância da educação para a saúde visando a autonomia dessas pessoas no desenvolvimento do autocuidado, melhorando assim sua auto-estima e o seu processo de socialização. Mas, além disso, nos propiciou também vislumbrar as diversas dimensões que contribuem com a organização do processo de cuidar em saúde para além do mero "prestar assistência", evidenciando formas de encaminhamentos que contribuem para a efetivação e ampliação dos direitos a saúde das pessoas que aí são cuidadas, ou seja, na perspectiva de que cuidar em saúde e emenfermagem também pode ser um ato político.

Nesta perpectiva, nos ativemos mais em aspectos do perfil socioeconômico dos sujeitos entrevistados que evidenciavam associações desfavoráveis para a emancipação do sujeito em uma situação crônica de saúde ou mesmo dificultavam na condução de sua vida cotidiana. A associação entre baixa renda familiar e baixa escolaridade, que predominou em dois terços da população estudada apontando para ganhos familiares abaixo de 3 salários mínimos mensais e ensino fundamental incompleto, nos aponta para um perfil preocupante quando nos reportamos a cidadania e ao respeito aos direitos, pois sabemos que quanto mais baixa a escolaridade mais desfavorável é o capital lingüístico dos sujeitos para questionar os profissionais acerca de seus problemas de saúde, do cuidado a ser efetivado e aos direitos que lhes são inerentes. Mas o fato de haver um perfil de baixa escolaridade não representa uma impossibilidade de atuação junto a essa população, pois a interação usuário/serviço/profissionais de saúde e educação tem proporcionado a superação das dificuldades impostas por essa variável.

Ampliando o perfil dos entrevistados pudemos perceber que a população estudada é composta, majoritariamente, por mulheres, sendo que essa caracterização por sexo se torna importante tendo em vista o fato de que novas demandas são impostas à família pela pessoa em situação crônica de saúde. Se essa família tem na figura da mãe/mulher um esteio não só financeiro, mas também de cuidados a todos os membros da família, haverá necessidade de novos arranjos para a adequação a nova situação. Este fato é agravado ao verificarmos que a maioria desses portadores de estomia teve como causa para realização da mesma o câncer, o que significa que terão o acréscimo ao fato de serem portadores de um dispositivo de estomia, o medo da recidiva ou da morte que o estigma do câncer agrega, o que os fragiliza ainda mais a pessoa e impõe ao trabalhador a necessidade de desenvolver um olhar solidário e para além da mera ajuda técnica.

Outro aspecto que investigamos foi o tipo de estoma de que o usuário é portador, sendo considerada a auto-referência para esse dado, com o intuito de podermos avaliar seus conhecimentos acerca do procedimento que sofreu. A colostomia foi referida por 15 dos entrevistados, sendo seguida a ileostomia com 02 pessoas e a urostomia também em 02 pessoas. Uma pessoa entrevistada refere que possui tanto colostomia como urostomia. Tivemos ainda 02 entrevistados que ignoravam o tipo de estoma que portavam. Este dado nos evidenciou que os usuários trocam informações entre si, o que é favorecido pela reunião de estomizados estimulada pela AMO e chama a atenção o fato que esse compartilhar informações e vivências ocorre também nas próprias instituições de saúde, nas salas de espera por atendimento, nas clinicas durante a internação, nos períodos que antecedem a cirurgia, evidenciando um usuário ativo na procura por informações e descaracterizando a idéia de que todos os usuários são passivos no processo de conhecimento acerca da própria saúde. Podemos perceber que o ser humano se reconstrói o tempo todo para se adaptar de forma criativa, sendo capaz de autonomia relativa quando se vê privado de certas disponibilidades ${ }^{1}$ como aquelas oriundas de ter suas funções fisiológicas de eliminação preservadas, compensando-as de outra maneira, fato que pode ser visualizado neste processo de reconstrução do ser na condição de pessoa portadora de estomia.

Quanto à permanência da estomia encontramos que 13 pessoas referem ser portadoras de estomia definitiva, 08 possuem estomia temporária e 01 das pessoas entrevistadas não soube informar esse dado. No que se refere ao tempo decorrido desde a realização da estomia tivemos 01 pessoa cuja abertura do estoma se deu há menos de um ano, 11 delas teve a cirurgia entre 01 e 02 anos e 07 estão convivendo com a estomia entre 02 e 05 anos. Apenas 02 pessoas convivem com a estomia há mais de 05 anos. Consideramos que quanto mais recente a situação de convivência com a estomia maiores são as dificuldades para manejar as novas necessidades e maiores os constrangimentos sofridos pelas pessoas, o que, consequentemente, gera necessidade de uma equipe 
eficiente e solidária com os limites impostos pela nova condição de vida destas pessoas.

Neste contexto atentamos que o perfil da população do Ambulatório de Ostomias nos apontou para a necessidade da educação para o autocuidado mais significativamente no período pós-operatório, uma vez que neste momento novos hábitos deverão ser incorporados no seu cotidiano, para que este usuário possa vir a ter uma melhor qualidade de vida após o procedimento. Se pensarmos nas enormes modificações que a confecção da estomia acarreta na vida de uma pessoa podemos avaliar a necessidade desse aprendizado ativo iniciado precocemente e com o acompanhamento e apoio constante dos profissionais da saúde.

Entre outros aspectos percebemos que o autocuidado deve ser precedido pelo contato da pessoa que ainda vai sofrer o procedimento com outros usuários que convivam com a estomia já há algum tempo, de maneira que possa haver a troca de experiência entre os mesmos. Em nosso Ambulatório estamos organizando o serviço neste sentido para que o desenvolvimento do autocuidado se dê de maneira segura e eficaz. Sabemos que estas aproximações precisam ocorrer no período anterior à confecção da da estomia, através da participação ativa da pessoa na qual será realizada a cirurgia, visto que, além de um direito que lhe é assegurado, ela poderá participar em todos os momentos das decisões acerca do procedimento que sofrerá em seu corpo e conhecerá as limitações que o mesmo lhe trará e como poderá adaptar-se a elas. É importante que conheça todos os cuidados em relação ao funcionamento e à manutenção da estomia, tais como, higiene freqüente do local para integridade da pele, observação das características normais da estomia em relação à cor, forma, tamanho e aspecto da mucosa, cuidados com os dispositivos, sendo que estes aspectos favorecem a diminuição da ocorrência de complicações, melhorando a qualidade de vida.

O início precoce desse aprendizado antes do procedimento, intensificado durante a hospitalização e mantido após a alta hospitalar tem como objetivos mais imediatos os de minimizar a ocorrência de complicações locais tais como edema, lesões da pele ao redor da estomia, hérnia, sangramento, infecção, estenose, prolapso ou retração. Todos podem, em alguma medida, ser resultantes de um cuidado inadequado do estoma e a aproximação entre os usuários mais antigos com os mais novos, pode minimizar estas complicações e trazer uma maior autonomia do estomizado, processo esse que é mediado pelos profissionais, alunos e docentes de enfermagem que atuam no local.

Embora saibamos que a educação para o autocuidado deva ser feita pelo conjunto dos profissionais da equipe de saúde, e que esta deveria ser composta por médico, enfermeiro, nutricionista, psicólogo, assistente social, todos interagindo ativamente com a pessoa portadora de estomia, isso ainda não acontece na realidade do serviço estudado. Mas, a equipe de enfermagem, os docentes e alunos bolsistas da pesquisa atuantes no ambulatório, vêm se organizando e tentando compensar a lacuna provocada por uma equipe incompleta se envolvendo, assim, nos diversos aspectos necessários ao cuidado correto e cidadão à pessoa portadora de estomia.

Há vários desdobramentos que evidenciam este trabalho da enfermagem, como por exemplo, o treinamento sistemático para a auto-irrigação da colostomia com desenvolvimento de material adaptado e de baixo custo e assim acessíveis aos usuários, o estímulo à participação nas reuniões desenvolvidas no Ambulatório, a confecção de material artesanal como cintos de tecido para substituir os cintos industrializados que são caros e quase inacessíveis para a maioria dos usuários do serviço. Percebemos que a constante presença dos docentes e alunos bolsistas envolvidos nos processos conjuntamente dirigidos de cuidado, ensino e pesquisa, vem contribuindo para a tessitura de um grupo cidadão, o que contribui, sobremodo, no processo emancipatório de todos os sujeitos envolvidos, quais sejam, usuários e seus familiares, profissionais da saúde, pesquisadores e alunos. Lembramos que complexo é tudo aquilo que é "tecido junto" e, dessa forma, estamos, como grupo de pesquisa, através desta atividade múltipla desenvolvida, plantando as sementes de um ensino baseado na pesquisa como principal atividade reflexiva. ${ }^{6}$

Portanto, educação política não se esgota na face propriamente política, mas inclui sempre a face técnica ligada a informação e ao ensino. Não poderia ser cidadania competente aquela desinformada, analfabeta, destituída de instrumentações técnicas para enfrentar a vida em sociedade. ${ }^{2}$ Trabalhar simultaneamente o ensino, a pesquisa e o processo de ser uma pessoa em situação crônica de saúde, implica em não só garantir os direitos mais evidentes, mas educar para que todos os sujeitos envolvidos venham a adquirir competência lingüística no sentido de serem protagonistas no processo de construção da sua cidadania. 
Um dos direitos garantidos as pessoas que vão sofrer uma estomia é a participação da pessoa na demarcação prévia do local onde esta será confeccionada. No entanto, em nosso estudo apenas dois dos entrevistados referiram ter participado do processo de escolha do local da estomia, sendo que um deles afirma ter sido apenas parcial essa participação. Aqui percebemos a necessidade de estimular um processo de auto-gestão junto a esses usuários, ou seja, propiciar condições para que estes possam vir a ter competência para conduzir o próprio destino. Assim, reiteramos a importância da educação para a emancipação pelo envolvimento de todos na compreensão de que o humano se constrói através da interação e da solidariedade para com o outro, o que subsidia fundamentalmente o processo de aprender por parte de alunos, docentes e técnicos e o processo de cuidar-se e autogerir-se diante dos limites impostos pela condição de ser estomizado por parte do usuário.

A formação e o fortalecimento de redes sociais é um dos caminhos mais promissores neste sentido, indo para além do cuidar-se como estomizado e exercendo a própria cidadania. A interação e a solidariedade que se constrói nas relações humanas pode ser visualizada na afirmação da maioria dos entrevistados sobre a presença ativa do enfermeiro e a de técnicos e auxiliares de enfermagem ao longo do período de adaptação a nova situação de vida.

\section{CUIDADO E EDUCAÇÃO PARA A SAÚDE: UMA CONSTRUÇÃO POLÍTICA NA PRÁ- TICA DOS PROFISSIONAIS DE ENFER- MAGEM}

Todos os trabalhos até agora desenvolvidos pelo GPESC têm visado desenvolver metodologias ativas que articulem o processo de pesquisar ao de assistir e de ensinar, pois entendemos que quando estes ocorrem em conjunto, envolvendo todos os sujeitos, todos simultaneamente aprendem e ensinam, independente do lugar de onde falem ou ajam. O envolvimento proporcionado pelo processo de cuidar é, em muito, ampliado quando associado ao processo de pesquisar, pois estimula a reflexão continua, uma vez que o foco dos estudos do grupo de pesquisa é pensar nos direitos à saúde de forma a estimular a cidadania, com a participação da enfermagem - alunos professores e técnicos - juntos nesse processo. Trouxemos a educação no processo de cuidar, cuidar-se e aprender em saúde e enfermagem como eixo maior dessa reflexão visto que é a partir dela que podemos entender como se dá a construção da politicidade para todos os sujeitos envolvidos, de maneira que estes possam vir a exercer efetivamente a sua cidadania no mundo da vida, da saúde e do trabalho.

Embora seja aqui descrito um panorama situacional inicial do atendimento oferecido pelos profissionais de saúde às pessoas portadoras de estomia no serviço estudado, faz-se necessário também dar relevância ao processo de ensino e pesquisa que vêm sendo desenvolvido por profissionais da Enfermagem para provocar mudanças na situação ainda pouco favorável imposta às pessoas em condições crônicas de saúde e que dependem quase que exclusivamente do Estado para cobrir as suas necessidades. Não é menos necessário considerar que tais mudanças, pelas imbricações com muitas outras dimensões, principalmente presentes em instâncias externas a própria instituição de saúde a qual o Ambulatório de Ostomias se vincula, são processuais e, como tal, se dão em espaços/tempos diversos.

Algumas dessas dimensões se desenham na própria implantação e organização do Ambulatório de Ostomia, que, embora tenha nove anos de funcionamento, sofre os revezes próprios das instituições públicas de saúde no que se refere ao suprimento adequado de recursos humanos, físicos e materiais para o seu trabalho. Também pelo fato de ser o único serviço no Estado que presta atendimento especializado a essa população influi de maneira decisiva na sua organização, visto que apresenta uma alta demanda de cuidado a pessoas portadoras de estomias vindas de todas as regiões do mesmo. Apesar da confecção da estomia nem sempre acontecer dentro da própria instituição, pois outras instituições também realizam esse tipo de cirurgia, todo o acompanhamento após a alta hospitalar e o oferecimento gratuito dos dispositivos se dá apenas no local do estudo.

Vemos, assim, que a implantação, organização e, principalmente, a manutenção de um serviço de saúde específico, como é o caso do atendimento no Ambulatório de Ostomias, não é trabalho fácil e acentuam-se as dificuldades quando essas atividades ficam a cargo de um único segmento profissional, no caso, a Enfermagem. Todos os demais profissionais têm tido uma atuação mais pontual vinculada ao período de hospitalização para a realização da estomia.

Como parte inerente a organização e funcionamento do serviço destaca-se a necessidade de identificação e caracterização da clientela atendida, a 
formalização dos documentos, tanto de identificação quanto de acompanhamento e cuidados oferecidos a essas pessoas, e também a elaboração de normas e rotinas de procedimentos e condutas e a educação permanente dos profissionais de enfermagem que os assistem. A ampliação do atendimento tem requerido também a ampliação da estrutura física e dos equipamentos necessários, bem como dos profissionais que prestam o cuidado, e a equipe de enfermagem, particularmente os enfermeiros e docentes, têm participação direta nestas reivindicações por melhores condições de trabalho e atendimento aos estomizados. Essas ações evidenciadas pelo fato de que, para a efetivação do direito já garantido por lei, quanto ao oferecimento gratuito dos dispositivos para a estomia, só se concretizou no Estado mediante os esforços intensos por parte dos profissionais enfermeiros em trabalho conjunto com os usuários do serviço.

Do esforço conjunto dos profissionais enfermeiros e das pessoas portadoras de estomia resultou também, como já dissemos anteriormente, na fundação da Associação dos Ostomizados de Mato Grosso (AMO), entidade cujo objetivo é a manutenção e ampliação dos direitos desse segmento da população. Embora com vinculação estreita ao Ambulatório de Ostomia desde a sua criação, tem sido buscado formas de promover a independência dessa Associação, para que esta possa vir a ter a autonomia necessária para atingir seus objetivos. É possível perceber que a efetivação dos direitos à saúde e a construção da cidadania é resultado de um processo longo e árduo que demanda a atuação intensa dos profissionais da saúde. Apesar dessa atuação não estar se dando de maneira equilibrada entre os diversos segmentos profissionais que atuam no serviço estudado, a enfermagem tem se destacado e empreendido esforços em todas as dimensões do processo em questão.

Como forma de efetivar a participação dos alunos, tornando-a parte inerente da formação profissional, tem sido estimulada, de maneira cada vez mais ampla, a integração dos alunos de enfermagem nesse espaço de aprendizagem e cuidado através do desenvolvimento de atividades de pesquisa e extensão. Dessa iniciativa nasceu, entre outros, o projeto de pesquisa que esta sendo base para a reflexão que aqui apresentamos. Lembramos que, a partir deste projeto maior, vêm sendo ampliados os estudos com vários sub-projetos específicos que visam organizar e ampliar o serviço oferecido, produzir novos conhecimentos e ampliar as práticas de cuidado de enfer- magem a pessoa portadora de estomias a partir do levantamento de suas reais necessidades de vida e saúde.

Essas pesquisas têm tido a preocupação de desenvolver temas específicos que ampliem os direitos à saúde dessa população, abordando questões tais como: a necessidade do desenvolvimento de meios alternativos e adaptações por parte das pessoas portadoras de estomia de maneira a suprir a demanda de produtos e equipamentos específicos para o seu auto-cuidado; a prática de cuidados com a estomia que buscam minimizar os desconfortos e complicações vivenciadas pelas pessoas que as possuem; a compreensão das repercussões sociais, sexuais, familiares, profissionais e financeiras que a realização da estomia trouxe para a vida dessas pessoas de acordo com as diversas fases da vida, o sexo, o tipo de estomia, dentre outros. Todos os estudos têm como foco principal o respeito aos direitos à saúde dentro do contexto do Sistema Único de Saúde.

Como resposta ao aumento do número de pessoas portadoras de estomia em todo o Estado, houve por parte dos enfermeiros e docentes que atuam nesse Ambulatório a reivindicação junto a Secretaria de Saúde do Estado para a ampliação da rede de serviço ambulatorial em outros pólos regionais de saúde. Essa demanda está em processo de efetivação, sendo que o primeiro passo foi dado através do oferecimento, por esses profissionais, do preparo dos enfermeiros que atuarão nos novos ambulatórios para o atendimento especializado às pessoas portadoras de estomias que residem em regiões mais distantes da capital.

Nosso intuito nesta reflexão foi explicitar o esforço que vem sendo empreendido pelos profissionais enfermeiros e docentes em dar concreticidade à dimensão política e a politicidade como arcabouço do processo educativo em saúde, tanto aquele voltado para a formação profissional como para a educação em saúde. Ao retratar o processo da construção da cidadania em um determinado espaço de atenção à saúde humana, estamos estimulando a enfermagem na busca pelo que poderíamos denominar cuidado emancipatório, ou seja, aquele que se re-elabora a partir de uma relação de poder mais simétrica estabelecida entre profissionais de saúde interessados nas pessoas por eles cuidadas. Nesta tipologia de cuidado inferimos a politicidade que pode estar presente no trabalho de cuidar, quando esse se dá de maneira solidária e se despe da roupagem de ajuda ou assistência que pressupõe a relação hierárquica entre sujeitos assimétricos. ${ }^{3}$ 
Se considerarmos a educação, em seu sentido amplo, como um processo capaz de desenvolver nas pessoas a consciência crítica das causas reais dos seus problemas e, ao mesmo tempo, criar uma prontidão para atuar no sentido da mudança, entenderemos que esse processo só é possível com a participação conjunta dos profissionais de saúde e das pessoas de quem cuidam.

E, se muito ainda há por ser construído no sentido de alcançar as condições necessárias para que as pessoas portadoras de estomias possam ser, elas próprias, instrumentos de mudança na sua situação de vida e saúde, temos que ter em mente também que a autonomia, seja ela a dos profissionais de saúde ou da pessoa portadora de estomia, só pode ser concebida em relação à idéia de dependências múltiplas, sendo, portanto, esse entendimento de autonomia como algo sempre relacional. ${ }^{6} \mathrm{Ou}$ seja, não nos tornamos autônomos sem a colaboração de outrem, e, nesse sentido, faz-se importante considerar que educar comporta sempre dois desafios difíceis de compor: há que se educar de maneira que o educando cada vez menos necessite de orientação, evitando, sempre a ilusão da não dependência entre quem aprende e quem ensina. ${ }^{1}$

Ao tratarmos da educação para a saúde tendo por foco o desenvolvimento do autocuidado e da cidadania essa autonomia implica em coresponsabilização dos profissionais de saúde para com as pessoas cuidadas, e também leva em consideração a necessidade de uma responsabilidade solidária que ofereça o apoio para a emancipação, visto que ninguém se emancipa sem ajuda, mas o resultado maior a ser buscado é saber viver sem ajuda. ${ }^{1}$

Entendemos ainda que, para que se ampliem as mudanças que já estão sendo empreendidas na situação inicialmente apresentada neste estudo é imprescindível que os profissionais de saúde conheçam os direitos da pessoa portadora de estomia e os reconheçam em cada momento da sua prática. Só assim podem desempenhar o cuidado emancipatório que busque compreender o contexto sócio-histórico onde são geradas as relações de ajuda-poder nas políticas de saúde e, assim, conseguir gerir as correlações de forças que estimulem o controle democrático e o reordenamento de poderes. Dessa forma se realiza uma gestão inteligente e capaz de oportunizar cenários propícios à desconstrução progressiva de assimetrias do poder tão comuns nas relações entre usuários e profissionais de saúde, onde acreditamos que o cuidar para a emancipação exige conhecer o outro para cuidar melhor.
Nesse sentido parece haver grande pertinência quanto à necessidade de que haja uma luta conjunta de profissionais e pessoas portadoras de estomias na efetivação e ampliação dos seus direitos, pois a cidadania organizada de maneira coletiva potencializa sumamente a competência para o confronto e para o consenso. $\mathrm{O}$ direito de associar-se vem antes de qualquer lei, pois é este direito que permite uma sociedade normatizada pela lei. ${ }^{8}$

Entendemos, assim, que a educação permanente iniciada ainda na formação dos profissionais de saúde e a educação para a saúde são dimensões complexas de um mesmo e único movimento rumo à emancipação das pessoas e ampliação da sua cidadania. Cuidar é "ajudar outra pessoa a obter auto-conhecimento, controle e auto-cura" Pensar cuidado, processo de pesquisa e ensino separadamente implica em equívocos que diminuem a capacidade de todos os sujeitos para a cidadania, pois, ao reiterar uma prática somente assistencialista, geramos dependência e não contribuímos para o aprender e ainda afastamos os sujeitos do processo de aproximar-se um do outro, um fato que contribui para a sensibilidade para o humano e para valores mais éticos e solidários no mundo do trabalho em saúde.

É preciso lembrar que os futuros possíveis de ampliação do direito e da cidadania se orientam mais pela educação do que pela assistência, ampliando a habilidade humana da politicidade, ou seja, aquela que possibilita o saber pensar e intervir, no sentido de atingir níveis crescentes de autonomia individual e coletiva que permitam a esses sujeitos construir e conduzir a sua própria história. ${ }^{1}$

\section{REFERÊNCIAS}

1 Demo P. Politicidade: razão humana. Campinas: Papirus; 2002.

2 Demo P. Pesquisa: principio científico e educativo. 11a ed. São Paulo: Cortez; 2005

3 Caponi S. Da compaixão à solidariedade: uma genealogia da assistência médica. Rio de Janeiro: Fiocruz; 2000.

4 Ministério da Saúde (BR), Conselho Nacional de Saúde, Comitê Nacional de Ética em Pesquisa em Seres Humanos. Resolução No 196 de 10 de outubro de 1996: diretrizes e normas regulamentadoras de pesquisa envolvendo seres humanos. Brasília(BR): O Conselho; 1996.

5 Maruyama SAT. A experiência da colostomia por câncer como ruptura biográfica na visão dos portadores, familiares e profissionais de saúde: um estudo etnográfico [tese]. Ribeirão Preto (SP): USP/EERP/Programa de Pós-Graduação em Enfermagem Fundamental; 2004. 
6 Morin E. Introdução ao pensamento complexo. Porto Alegre: Sulina; 2005.

7 Pires MRM. Politicidade do cuidado como referência emancipatória para a gestão de políticas de saúde: conhecer para cuidar melhor, cuidar para confrontar, cuidar para emancipar [tese]. Brasília (DF): UnB/ Programa de Pós-Graduação em Política Social; 2004.
8 Demo P. Cidadania pequena. Campinas: Editores Associados; 2001.

9 Souza ML, Sartor VV, Padilha MICS, Prado ML. O cuidado em enfermagem: um aproximação teórica. Texto Contexto Enferm. 2005 Abr-Jun; 14 (2): 266-70. 